\title{
What Makes Scientific Workflows Scientific?
}

\author{
Bertram Ludäscher \\ University of California, Davis \\ ludaesch@ucdavis. edu
}

A scientific workflow is the description of a process for accomplishing a scientific objective, usually expressed in terms of tasks and their dependencies [5]. While workflows have a long history in the database community as well as in business process modeling (where they are also known as business workflows), and despite some early works on scientific workflows 310, the area has only recently begun to fully flourish (e.g., see 12297411]). Similar to scientific data management which has different characteristics from traditional business data management 8], scientific workflows exhibit new challenges and opportunities that distinguish them from business workflows. We present an overview of these challenges and opportunities, covering a number of issues such as different models of computation, scalable data and process management, and data provenance and lineage handling in scientific workflows.

\section{References}

1. Fox, G.C., Gannon, D. (eds.): Concurrency and Computation: Practice and Experience. Special Issue: Workflow in Grid Systems, vol. 18(10). Wiley \& Sons, Chichester (2006)

2. Gil, Y., Deelman, E., Ellisman, M., Fahringer, T., Fox, G., Gannon, D., Goble, C., Livny, M., Moreau, L., Myers, J.: Examining the Challenges of Scientific Workflows. Computer 40(12), 24-32 (2007)

3. Ioannidis, Y.E., Livny, M., Gupta, S., Ponnekanti, N.: ZOO: A Desktop Experiment Management Environment. In: VLDB, pp. 274-285 (1996)

4. Ludäscher, B., Altintas, I., Berkley, C., Higgins, D., Jaeger, E., Jones, M., Lee, E.A., Tao, J., Zhao, Y.: Scientific Workflow Management and the Kepler System. Concurrency and Computation: Practice \& Experience 18(10), 1039-1065 (2006)

5. Ludäscher, B., Bowers, S., McPhillips, T.: Scientific Workflows. In: Özsu, M.T., Liu, L. (eds.) Encyclopedia of Database Systems. Springer, Heidelberg (to appear, 2009)

6. Ludäscher, B., Goble, C. (eds.): ACM SIGMOD Record: Special Issue on Scientific Workflows, vol. 34(3) (September 2005)

7. Oinn, T., Addis, M., Ferris, J., Marvin, D., Senger, M., Greenwood, M., Carver, T., Glover, K., Pocock, M., Wipat, A., Li, P.: Taverna: a tool for the composition and enactment of bioinformatics workflows. Bioinformatics 20(17) (2004)

8. Shoshani, A., Olken, F., Wong, H.K.T.: Characteristics of Scientific Databases. In: VLDB, pp. 147-160. Morgan Kaufmann, San Francisco (1984)

9. Taylor, I., Deelman, E., Gannon, D., Shields, M. (eds.): Workflows for e-Science: Scientific Workflows for Grids. Springer, Heidelberg (2007)

10. Wainer, J., Weske, M., Vossen, G., Medeiros, C.B.: Scientific Workflow Systems. In: Proceedings of the NSF Workshop on Workflow and Process Automation in Information Systems: State of the Art and Future Directions (1996)

11. Yu, J., Buyya, R.: A Taxonomy of Scientific Workflow Systems for Grid Computing. In: Ludäscher and Goble [6] 